\title{
A Proposed Adaptive Scheme for Arabic Part-of Speech Tagging
}

\author{
Mohammad Fasha \\ Department of Computer Science \\ King Abdulla II School for Information Technology \\ The University of Jordan, Amman
}

\begin{abstract}
This paper presents an Arabic-compliant part-ofspeech (POS) tagging scheme based on using atomic tag markers that are grouped together using brackets. This scheme promotes the speedy production of annotations while preserving the richness of resultant annotations. The proposed scheme is comprised of two main elements, a new tokenization approach and a custom tool that enables the semi-automatic implementation of this scheme. The proposed model can serve in many scenarios where the user is in a need for better Arabic support and more control over the Part-of-Speech tagging process. This scheme was used to annotate sample narratives and it demonstrated capability and adaptability while addressing the various distinguishing features of Arabic language including its unique declension system. It also sets new baselines that are prospect for further exploration by future efforts.
\end{abstract}

Keywords-Arabic natural language processing (ANLP); partof-speech (POS) tagging; part-of-speech tokenization scheme; morpho-syntactic tagging; Arabic declension system

\section{INTRODUCTION}

Part-of-Speech (POS) tagging is the process of classifying and labeling words in a sentence according to their grammatical categories, i.e., verbs, nouns, particles, ... etc. [1]. It is considered as an important step in many Natural Language Processing (NLP) implementations [2] as it deliver a layer of abstraction over the vast variances of the lexical, syntactic and semantic content of natural language. This generalization process renders that vast amount of knowledge into controllable artifacts that are valuable for many related implementations.

In contrast to other languages, Arabic has several distinguishing and challenging features, more importantly, its rich morphology and highly inflectional nature. A single Arabic word can bear more meaning than it's English counterparts [3]. Therefore and more often, information is either lost or misrepresented using the conventional Part-ofSpeech tagging schemes. Moreover, there is a noticeable shortage in terms of standards related to Arabic Part-ofSpeech tagging schemes, whether for the used tagsets or for the tokenization process [4], [5].

To assist in mitigating some of these challenges, we propose a new Part-of-Speech tagging scheme that can provide rich annotations while being simpler and less demanding than the detailed parsing of corpora, which is cumbersome and time consuming [6]. The scheme we are proposing is based on using tagsets of atomic tag markers that can be aggregated and grouped together using brackets. Having such arrangements, users are provided with fundamental baselines that enable them to seamlessly commence with a rich morpho-syntactic annotation process for Arabic text.

The contributions of this work includes the definition of a declension system (نظام الاعراب) complaint morpho-syntactic tagging scheme that promotes simplicity, clarity and agility of the produced annotations as well as the tagging process itself. Further, to the best of our knowledge, this is one of the rare studies that surveys Arabic Part-of-Speech tagging schemes and discusses their pros and cons. This important subject needs further investigation due to the unique linguistic features of Arabic language, while most related work concentrates on establishing rule-based or statistical motivated Part-of-Speech taggers and morphology analyzers.

This paper is structured as follows. In Section II, we present a brief introduction about the distinguishing features of Arabic language. In Section III, we discuss the related previous work. Section IV presents some of the challenges that are related to the conventional Arabic Part-of-Speech tagging schemes. In Section V, the proposed tagging scheme is presented in more detail. Section VI presents the custom annotation tool. Section VII presents a sample narrative annotated using the proposed scheme and finally in Section VIII we present the conclusion and the suggested future work.

\section{ARABIC Distinguishing FEATURES}

Arabic is a Semitic language spoken by over 300 million speakers in 22 Arabic countries, it has a liturgical importance as it is the language of Quran, the Holy book for over 1.2 billion Muslims around the world [7].

In contrast to many other languages i.e. Indo-European languages, Arabic has many distinguishing features. These features are related to its rich morphology, highly inflectional nature, subject dropping, free words order, short vowels omission, large lexicon and vocabulary and many others [8], [9]. Accordingly, it is quite often challenging to identify the correct Part-of-Speech of a given word under a certain context.

The rich morphology of Arabic can be related to its template nature where new words are derived from root ones by applying a set of fixed patterns. In addition, Arabic has a concatenate nature where words (nouns and verbs) are inflected to indicate different senses. For example, Arabic 
nouns can be inflected to indicate number (singular, dual, plural), gender (masculine, feminine), definiteness (definite, indefinite) and case (nominative, accusative, genitive) as well as possession. Similarly, Arabic verbs are inflected to indicate aspect (perfective, imperfective, imperative), voice (active, passive), tense (past, present, future), mood (indicative, subjunctive, jussive), subject (person, number, gender) as well as object clitics. In addition, Arabic words can be prefixed with functional morphemes (single particles or prepositions) to indicate various senses (causality, conjunctions, assertion, inquiry, association ... etc.).

To demonstrate the richness of Arabic language and the amount and diversity of information that can be convoyed in a single word, we consider the surface word (wa sa nokhberu hum, وسنخبر هم, and we shall inform them) as an example. This single word is comprised of the following constituents:

- The proclitic morpheme (wa, 9 , and) which indicates coordinating conjunction.

- The proclitic morpheme (sa,w, shall) which indicates a future event.

- The inflection particle (nun, ن) which indicates first voice plural speaker (us).

- The stem (khabara, خبر, tell) which is the verb itself.

- Finally, the enclitic morphemes (hum, ه, them) which is an attached pronoun that indicates a plural object of the verb.

In [10], the author provides a more detailed discussion about Arabic morphology and its distinguishing features. Nevertheless, annotating the previous sample word with a verb marker (VB) according to its grammatical category shall waste numerous information. Therefore, a viable Arabic partof-speech tagging scheme has to possess the capacity to address Arabic distinguishing features and to accurately classify Arabic words without losing information or creating ambiguities. In order to be able to support the distinguishing features of Arabic language, the required part-of-speech tagging scheme has to be able to fully support Arabic's declension system (نظام الاعراب).

In the next section, we present a brief discussion about the related previous work and highlight their main challenges.

\section{RELATED WORK}

A limited number of part-of-speech Taggers were presented for Arabic language [11]. Generally, these automated taggers can be classified under three main schemes: the statistical-based schemes, the rule-based schemes and the hybrid ones [2]. More importantly, reviewing the previous related work, we noticed an overlapping between part-ofspeech tagging and morphology analyses process. For example, Stanford NLP toolkit uses the reduced Penn tagset, while others like the Buckwalter AraMorph incorporates the syntactic category of a given word within the generated morphology analyses results.

Nevertheless, in this work, we are interested in the part-ofspeech annotating scheme and format that was implemented by every one of these tools. We start our listing with an early effort that was presented by [12] who introduced a hybrid algorithm for Arabic part-of-speech tagging. That algorithm used a custom tagset comprised of (130) fixed morphosyntactic markers that were defined based on Arabic grammar rules. Each marker identifies the grammatical category and the inflections of a given word. For example, a perfect verb in the second person masculine plural form is annotated using the (VPP12M) marker and a singular masculine accusative definite adjective is annotated using the (NACSgMAD) marker.

An interesting tagging scheme was presented in Arabic Treebank (ATB) project [13]. That tagging scheme was based on the well-known rule-based Buckwalter Arabic Morphology Analyzer (BAMA) [14]. (BAMA) uses around (70) basic tag markers that can be combined together to form a larger number of composite tags. For example, in (BAMA), the (IV_PASS) marker indicates imperfective passive verb, three types of information are aggregated together in that composite tag, i.e., imperfect, passive and verb. (BAMA) include tags for indicating person, voice, mood and aspect for verbs, and gender and number for their subjects. It also includes gender, number, case and state for different types of nominals [5].

Another important tagging scheme was introduced by the Prague Arabic Dependency Treebank (PADT) project that was presented in [15]. In that work, a multi-level annotation scheme for a selected corpus was implemented. The first level of annotation involved the morphology analyses of Arabic words. For that part, a morphology compliant tagset was used to construct a (15) slots structure covering the various morphological aspects of a given word i.e. gender, number, person, aspect ... etc. In PADT, a single character represented each morphology feature. A challenge in (PADT) tagging scheme was that the meaning of the same character might differ according to a specific internal structuring procedure. For example, the letter $(\mathrm{P})$ on the second position is to be read as Passive Particle if it was preceded by an (N, Noun), and as a Perfect if it was preceded by a (V, Verb). This arrangement requires specialized skills and knowledge to able to use and interpret (PADT) tagging scheme [16].

Similarly, CATiB project [17] presented an Arabic Treebanking scheme that was designed with the motivation of providing rich annotations while being simpler than other similar efforts i.e. ATB and PADT. The focus of CATiB was primarily on the speedy production of the manually annotated corpus while the inspiration was not to duplicate information that could be extracted or indicated by other means, i.e., by syntactic analysis. Consequently, CATiB introduced a succinct (POS) tagset comprised of (6) POS tags which are: NOM for nominals. PROP for proper nouns, VRB for activevoice verbs, and VRB-PASS for passive- voice verbs, PRT for particles and PNX for punctuations. Other markers were identified for the deeper level of syntactic-motivated annotations.

In [18], authors presented a functional based (POS) tagset where words are tokenized and (POS) tagged based on their grammatical functions rather than their morpho-syntactic structure. For example, the sentence (زمانها خلصت المسيرة, the march must have finished) is labeled as a modal (MD) 
although the direct (POS) for the Arabic word (زمان, Time) is (NN, Noun).

A relatively recent effort was introduced by [11] who presented a systematic scheme for establishing Arabic compliant tagsets. In that work, a three level categorization of Arabic morpho-syntactic tagsets was defined. The first level was comprised of 7 tags, the inner level included 23 tags while lower level included 54 tags. Accordingly, the user of the system can use the depth of tagging that can better address his needs.

Finally, [2] and [5] presented interesting reviews on Arabic part-of-speech taggers and tagsets where the former concentrated on tagsets while the later presented a listing of the most prominent taggers along with a discussion about their challenges and limitations.

\section{Challenges Related to the EXISTING ARABIC (POS) SCHEMES}

The review process that was presented in the previous section revealed several challenges and limitations that are related to the existing tagging schemes. To further assess these schemes, we examined a number of the accessible taggers and morphology analyzer which included Stanford NLP toolkit [19], NLTK toolkit [20], AL-Khalil morphology analyzer [3], BAMA morphology analyzer [14] as well as MADAMIRA [21] and SAFAR platforms [22]. Table 1 below presents a listing of the results that were captured while examining these tools over a sample sentence. Analyzing the results from a linguistic perspective, we concluded to the following list of observations:

a) There is no standardized or a community adopted (POS) scheme for Arabic language. Our examination revealed that different (POS) tagsets were used by different (POS) taggers; some of these tagsets were generalized while others were more detailed to better address Arabic distinguishing features. The observation was also noted by [4]. Similarly, the tokenization scheme of the tag markers is also different in each tool.

b) The accuracy of the examined (POS) taggers was questionable. For example, Stanford NLP produced numerous errors in the generated tagging such as the noun (كرته, his ball) which was annotated as (NNP) or a proper noun. Similarly, and for a different sample sentence, MADAMIRA identified the word (شعر, felt) as a noun (poetry) rather than a verb, also the verb (حضر, came) was identified as a verb inflected for third person singular masculine while the correct interpretation according to the context was a third person plural masculine. Likewise, the verb (خدعتكم. I deceived you) was identified as a verb inflected with a third person singular feminine subject while it was masculine according to the context. Moreover, the library failed to analyze some words e.g. (مسرعين, in a hurry) which were tagged as NOANALYSIS.

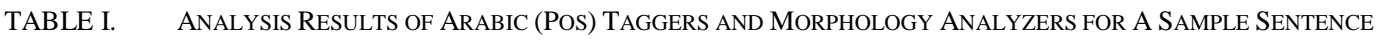

\begin{tabular}{|c|c|c|c|c|c|}
\hline $\begin{array}{c}\text { Arabic } \\
\text { Sentence }\end{array}$ & وركل & كرته & فاتجهت & نحو الزجاج & فحطمته \\
\hline $\begin{array}{c}\text { English } \\
\text { Translation }\end{array}$ & $\begin{array}{c}\text { and he } \\
\text { hit/inflected as } \\
\text { Singular } \\
\text { Masculine } \\
\text { Subject } \\
\text { Inflection }\end{array}$ & $\begin{array}{l}\text { his ball/ attached possession } \\
\text { pronoun }\end{array}$ & $\begin{array}{c}\text { So it went } \\
\text { Singular Feminine } \\
\text { Subject Inflection }\end{array}$ & $\begin{array}{l}\text { towards the } \\
\text { window/glass }\end{array}$ & $\begin{array}{c}\text { so it broke it/inflected as Singular } \\
\text { Feminine Subject }+ \text { Singular } \\
\text { Masculine Object }\end{array}$ \\
\hline $\begin{array}{c}\text { Buckwalter } \\
\text { Transliteration }\end{array}$ & wrkl & krth & fitajahat & naHow AlzujAj & fHTmt \\
\hline Stanford NLP & الوركل & & & 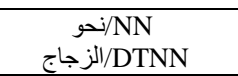 & ا \\
\hline Al-Khalil & $\begin{array}{lr}12 \text { solutions, } \\
\text { verbs and } \\
\text { gerunds }\end{array}$ & $\begin{array}{l}17 \text { solutions, verbs, nouns and } \\
\text { gerunds }\end{array}$ & 5 solutions, verbs & $\begin{array}{l}15 \text { solutions for } \\
\text { both }\end{array}$ & 13 solutions, verbs and gerunds \\
\hline ВАMA & $\begin{array}{l}2 \text { solutions } \\
\text { including } \\
\text { VERB_PERFE } \\
\text { CT } \\
\text { and } \\
\text { NOUN }\end{array}$ & 6 solutions, NOUN & $\begin{array}{l}6 \text { solutions including } \\
\text { VERB_PERFECT } \\
\text { With different subject } \\
\text { inflections }\end{array}$ & $\begin{array}{l}4 \text { solutions for } \\
\text { naHowa and } 5 \\
\text { solutions for } \\
\text { AlzujAj }\end{array}$ & $\begin{array}{l}\text { solutions } \\
\text { VERB_PERFECT } \\
\text { Different Subject and Object } \\
\text { inflections }\end{array}$ \\
\hline SAFAR & $\begin{array}{l}7 \text { solutions, } \\
\text { different } \\
\text { subjects } \\
\text { inflections }\end{array}$ & $\begin{array}{l}15 \text { solutions, different subjects and } \\
\text { objects inflections }\end{array}$ & $\begin{array}{l}4 \text { solutions, different } \\
\text { subject inflections }\end{array}$ & $\begin{array}{lr}14 \text { solutions } & \text { for } \\
\text { naHowa and } 17 \\
\text { solutions for } \mathrm{Al} \\
\text { zujAj }\end{array}$ & $\begin{array}{l}12 \text { solutions, different subjects } \\
\text { and objects inflections }\end{array}$ \\
\hline MADAMIRA & $\begin{array}{l}\text { wa/CONJ+rakal } \\
\text { /PV+a/PVSUFF } \\
\text { _SUBJ:3MS }\end{array}$ & $\begin{array}{l}\text { kur/NOUN+ap/NSUFF_FEM_SG } \\
\text { +a/CASE_DEF_ACC+hu/POSS_ } \\
\text { PRON_3MS }\end{array}$ & $\begin{array}{l}\text { fa/CONJ+\{it ajah/PV+ } \\
\text { at/PVSUFF_SUBJ:3FS }\end{array}$ & $\begin{array}{l}\text { naHowa/PREP } \\
\text { A1/DET+zujAj/NO } \\
\text { UN+a/CASE_DEF } \\
\text { _ACC }\end{array}$ & $\begin{array}{l}\text { fa/CONJ+HaT am/PV+at/PVSU } \\
\text { FF_SUBJ:3FS+hu/PVSUFF_DO: } \\
\text { 3MS }\end{array}$ \\
\hline
\end{tabular}

c) Some of the examined tools were not suitable for automated (POS) processing as they generate all the possible interpretations for a given word. This observation was noticed in BAMA and AL-Khalil morphology analyzers. Moreover, Al-Khalil does not employ any (POS) tokenization scheme, 
To enable the aforementioned objectives, the proposed scheme was based on the following design principles:

a) All the defined tag markers in the scheme were standalone and atomic. Each marker is self-explaining and self-contained and clearly defines a single concept e.g. gender, number, case, mood...etc. This design principle promotes the clarity of markers and ensures that no duplication or overlapping between markers can occur. For example, if a marker indicates a certain concept e.g. FEM for feminine gender, this same marker will be used for all words categories that might be inflected to indicate gender i.e. nouns, verbs, adjectives, pronouns, relative pronouns...etc. No other marker will be used for the same concept regardless of the word category. Therefore, the challenges that were stated in items g)) and h)) of section IV cannot occur.

b) Composite markers are established as aggregates of the basic and atomic ones. For instance, a plural noun is represented using the (NN) marker and the (PLR) marker, not with a single marker i.e. (NNS), for both concepts. This design principle preserves clarity and allows extendibility using clear composition of markers; it also facilitates string-based matching operations that can be implemented over part-ofspeech annotations.

\section{B. Initial (POS) Tagset}

The definition of a coherent Arabic-compliant tagset is out of the scope of our current work. In [11] and [25], the authors provided interesting guidelines that can assist in defining an Arabic-compliant tagset in a more systematic manner.

Nevertheless, for assessing our proposed model, we established an initial tagset to demonstrate the capability of the scheme and the diversity of markers that it can seamlessly support. This initial tagset (presented in Appendix A) classify the tag markers according to the following categories:

\section{- Lexical markers:}

This category includes the basic grammatical classification of words according to Arabic language rules. This includes the classification of nominals, verbs and particles, the three main Arabic word types along with their direct subsets.

- Morphology related markers:

This includes the markers that identify affixations and inflections related to nouns and verbs.

- Functional markers:

Functional markers include the tags that indicate the functional role of a given lexical entity. This includes senses of causality, modality, time and space relations, assertion, confirmation, negation, sequencing and conjunction coordination as well as others.

- Arabic declension system:

This category includes markers that are related to case definitions for Arabic nouns and mood definitions for Arabic verbs, as well as other features that signals specific insights that are related to Arabic language e.g. (Kana and its sisters,

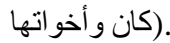

\section{The Proposed Tokenization Scheme}

A main objective of the proposed model was to better support Arabic declension system i.e. (نظام الاعراب) where the user is able to employ adequate combination of markers that can better satisfy his needs and his language proficiency.

Having an extended and diverse tag set, it was important to define an adaptive, dynamic and flexible tokenization scheme that can utilize these diverse markers in a simple, clear and agile manner.

Two types of brackets were employed to establish the proposed tokenization scheme, the round brackets or parenthesis "( )" and the braces or the curly brackets " \{\} ". Using these brackets, different levels of grouping and hierarchies could be established to annotate different word categories. The parentheses are used to establish word level groupings while the curly brackets are used to create token level annotations. This arrangement combines concepts from conventional Part-of-Speech tagging, morphology analysis as well as syntactic tree parsing as a single Arabic word can encompass a multi-token paragraph according to its morphology.

To demonstrate the proposed bracketing scheme, we consider the sample surface word that was presented in Section 2 (wa sa nokhberu hum, وسنخبر هم, and we shall inform them). Using the proposed scheme, this single word is annotated as following:

- $\{\mathrm{RP}+\mathrm{WA}+\mathrm{CC}\}$ : The proclitic morpheme (wa, g, and) which indicates coordinating conjunction particle.

- $\{\mathrm{RP}+\mathrm{SA}+\mathrm{FTR}\}$ : The proclitic morpheme (sa,w, shall) which indicates a future event particle.

- $\{$ PLRL+stV\}: The inflection particle (nun, ن) which indicates first voice plural speaker (us).

- $\{\mathrm{VB}\}$ : The stem (khabara, خبر, tell) which is the verb itself.

- $\{$ PRN+SFX_OBJ+PLRL+MSC $\}$ : The enclitic morphemes (hum,», them) which is an attached pronoun that indicates a plural masculine object.

While the composite tag for this word is defined as following:

$(\{\mathrm{RP}+\mathrm{WA}+\mathrm{CC}\}\{\mathrm{RP}+\mathrm{SA}+\mathrm{FTR}\}\{\mathrm{VB}+\mathrm{PLRL}+\mathrm{stV}\}\{\mathrm{PRN}+$ $\mathrm{SFX}+\mathrm{OBJ}+\mathrm{PLRL}+\mathrm{MSC}\})$

\section{Advantages of the Proposed Scheme}

To demonstrate the advantages of the proposed tagging scheme over other available schemes, we performed several examinations for annotation sample words using Stanford (POS) tagger, MADAMIRA morphology analyzer and the proposed scheme. 
TABLE II. COMPARING THE PRoposed SCHEME AgAinst OTHER SCHEMES

\begin{tabular}{|c|c|c|c|c|c|}
\hline & $\begin{array}{l}\text { Annotation } \\
\text { Scenario }\end{array}$ & Sentence Sample & $\begin{array}{l}\text { Stanford } \\
\text { (POS) } \\
\text { Tagger }\end{array}$ & $\begin{array}{l}\text { MADAMIRA Morphology Analyzer } \\
\text { Scheme }\end{array}$ & Proposed Scheme \\
\hline 1 & Composite words & شاهدته She saw him & VBD & $\begin{array}{l}\text { \{bw:\$Ahad/PV+tu/PVSUFF_SUBJ:1S+hu/PV } \\
\text { SUFF_DO:3MS }\}\end{array}$ & $\begin{array}{l}\text { (\{VBD+SNG+FEM+rdV }\} \\
\{\mathrm{SFX}+\mathrm{OBJ}+\mathrm{PRN}+\mathrm{SNG}+\mathrm{MSC} \\
\})\end{array}$ \\
\hline 2 & $\begin{array}{l}\text { Kana and its sister } \\
\text { كان واخو اتها }\end{array}$ & $\begin{array}{l}\text { كاتت السماء ماطرة } \\
\text { The sky was raining }\end{array}$ & VBD & $\begin{array}{l}\text { \{bw:kAn/PV+ } \\
\text { at/PVSUFF_SUBJ:3FS }\}\end{array}$ & $\begin{array}{l}(\{\mathrm{VBD}+\mathrm{KANA}+\mathrm{SNG}+\mathrm{FEM}+1 \\
\mathrm{dV}\})\end{array}$ \\
\hline 3 & $\begin{array}{l}\text { ENNA and its sister } \\
\text { إنَّ وأخو اتها }\end{array}$ & $\begin{array}{l}\text { انهاتمطر بغزارة } \\
\text { It is raining heavily }\end{array}$ & VBP & $\left\{b w:<\right.$ in $\left.\sim a / F U N C \_W O R D+h A / P R O N \_3 F S\right\}$ & $\begin{array}{l}(\{\mathrm{IN}+\mathrm{ENNA}\}\{\mathrm{PRN}+\mathrm{SNG}+\mathrm{FE} \\
\mathrm{M}+\mathrm{rdV}\})\end{array}$ \\
\hline 4 & إِن: gloss: if/whether & $\begin{array}{l}\text { انٍ تدرس تنجح you succeed } \\
\text { If you study you }\end{array}$ & IN & $\{$ bw: $<$ in/FUNC_WORD $\}$ & $(\{\mathrm{IN}+\mathrm{CND}\})$ \\
\hline 5 & $\begin{array}{l}\text { Active Participle } \\
\text { اسم الفاعل }\end{array}$ & $\begin{array}{l}\text { هي ذاهبه } \\
\text { I am going }\end{array}$ & $\mathrm{JJ}$ & $\{$ bw:*Ahib/ADJ+ap/NSUFF_FEM_SG $\}$ & $\{\mathrm{AP}+\mathrm{SNG}+\mathrm{FEM}\}$ \\
\hline 6 & $\begin{array}{l}\text { Passive Participle } \\
\text { اسم الكفوول }\end{array}$ & $\begin{array}{l}\text { He is oppressed } \\
\text { Hظو }\end{array}$ & NNP & $\{$ bw:maZoluwm/ADJ $\}$ & $\{\mathrm{PP}+\mathrm{SNG}+\mathrm{MSC}\}$ \\
\hline 7 & $\begin{array}{l}\text { Relative Pronouns } \\
\text { الاسماء الموصوله }\end{array}$ & $\begin{array}{l}\text { الطفل الذي ييكي } \\
\text { The baby that is crying }\end{array}$ & WP & $\{$ bw:Al a*iy/REL_PRON $\}$ & $(\{\mathrm{RPRN}+\mathrm{SNG}+\mathrm{MSC}\})$ \\
\hline 8 & $\begin{array}{l}\text { Demonstrative } \\
\text { Pronouns } \\
\text { ضمائر الاشارة }\end{array}$ & $\begin{array}{l}\text { ذناب } \\
\text { This is my book } \\
\text { ذلتك كتابي } \\
\text { That is my book }\end{array}$ & $\begin{array}{l}\text { DT } \\
\text { DT }\end{array}$ & $\begin{array}{l}\left\{\mathrm{bw}: h^{` * A} / \mathrm{DEM} \text { PRON_MS }\right\} \\
\left\{\mathrm{bw}:{ }^{` *} * \text { A/DEM_PRON_MS }\right\}\end{array}$ & $\begin{array}{l}(\{\mathrm{PRN}+\mathrm{SNG}+\mathrm{MSC}+\mathrm{NR}\}) \\
(\{\mathrm{PRN}+\mathrm{SNG}+\mathrm{MSC}+\mathrm{FR}\})\end{array}$ \\
\hline 9 & Pronouns & $\begin{array}{l}\text { هي تلعب بالكرة } \\
\text { She is playing with the ball } \\
\text { الت تلعبين بالكرة } \\
\text { You are playing with the ball }\end{array}$ & $\begin{array}{l}\text { PRN } \\
\text { PRN }\end{array}$ & $\begin{array}{l}\{\text { bw:hiya/PRON_3FS }\} \\
\{\text { bw:hiya/PRON_2FS }\}\end{array}$ & $\begin{array}{l}(\{\mathrm{PRN}+\mathrm{SNG}+\mathrm{FEM}+\mathrm{rdV}\} \\
(\{\mathrm{PRN}+\mathrm{SNG}+\mathrm{FEM}+\mathrm{ndV}\}\end{array}$ \\
\hline 10 & $\begin{array}{l}\text { Distinguish } \\
\text { Prepositions }\end{array}$ & $\begin{array}{l}\text { ذهبنا الى المدرسة } \\
\text { We went to school } \\
\text { جلسنا على المقعد } \\
\text { We sat on the chair }\end{array}$ & $\begin{array}{l}\text { IN } \\
\text { IN }\end{array}$ & $\begin{array}{l}\{\text { bw: }<\text { ilaY/PREP }\} \\
\{\text { bw:EalaY/PREP }\}\end{array}$ & $\begin{array}{l}\{\mathrm{RP}+\mathrm{ELA}\} \\
\{\mathrm{RP}+\mathrm{ALA}\}\end{array}$ \\
\hline 11 & $\begin{array}{l}\text { Gender and Number } \\
\text { Markers for Nouns }\end{array}$ & شاهدت السماء & DTNN & $\begin{array}{l}\text { \{bw:Al/DET+ } \\
\text { samA'/NOUN+ } \\
\text { u/CASE_DEF_NOM }\}\end{array}$ & $\{\mathrm{DT}+\mathrm{NN}+\mathrm{SNG}+\mathrm{FEM}+\mathrm{CSN}\}$ \\
\hline 12 & Adverbs of manner & $\begin{array}{l}\text { ركض الولد سبريعا } \\
\text { The boy ran quickly }\end{array}$ & $\mathrm{JJ}$ & $\{$ bw:sariyE/ADV+AF/CASE_INDEF_ACC $\}$ & $(\{\mathrm{RB}+\mathrm{MNR}\})$ \\
\hline 13 & Interrogative Nouns & $\begin{array}{l}\text { S } \\
\text { How much } \\
\text { مhen } \\
\text { When } \\
\text { How } \\
\text { How } \\
\text { Where } \\
\text { نd } \\
\text { Whose }\end{array}$ & $\begin{array}{l}\text { WRB } \\
\text { WRB } \\
\text { WRB } \\
\text { WRB } \\
\text { WP\$ }\end{array}$ & $\begin{array}{l}\{\text { bw:kam/INTERROG_PART }\} \\
\{\text { bw:mataY/INTERROG_PART }\} \\
\{\text { bw:kayofa/INTERROG_PART }\} \\
\{\text { bw:>ayona/INTERROG_PART }\} \\
\{\text { bw:li/PREP+man/INTERROG_PART }\}\end{array}$ & $\begin{array}{l}(\{\mathrm{WP}+\mathrm{QTY}\}) \\
(\{\mathrm{WP}+\mathrm{TIM}\}) \\
(\{\mathrm{WP}+\mathrm{MNR}\}) \\
(\{\mathrm{WP}+\mathrm{LOC}\}) \\
(\{\mathrm{WP}+\mathrm{POSS}\})\end{array}$ \\
\hline
\end{tabular}

Stanford tagger produces basic syntactic based tag markers for Arabic, while MADAMIRA provides a more extended version of markers that includes syntactic word classifications as well as the morphology analysis related ones. Table 2 below presents a listing of the gathered results.

As demonstrated in the table, the proposed scheme can deliver the same set of capabilities that are provided by the other models only it has the following additional advantages:

- The format of the proposed tagging scheme falls between the briefed Stanford format and the extended format of MADAMIRA. Nevertheless, the proposed scheme provides all the information that is delivered by those two schemes in a simplified manner that includes the syntactic word type classification as well as the morphology related ones.

- The use of brackets eliminates and substitutes the explicit tokenization of composite words. As demonstrated in the first sample, that composite word is comprised of two parts, the perfect verb and the attached pronoun. Curly brackets surround each of these two word parts and parenthesis surrounds the whole string. While in the other schemes, the aggregation is achieved by attaching characters together without any separators or using separators such as the underscore marker " ", the plus sign "+", the colons ":", as well as other approaches e.g. PV+PVSUFF_SUBJ:3MS. 
- The proposed scheme does not use single-character markers as they can create ambiguities and overlaps. Rather, multi-character atomic tag markers are used to establish a self-explaining set of annotations.

- Also, unlike [12], [14], [16], [17], no aggregate markers are used in the proposed scheme, rather, all aggregations are established using the plus sign "+" character which is inserted between the atomic markers. Reference [26] presents an interesting listing for tokenization alternatives that are used by a number of different schemes. While in the previous efforts, different approaches where employed to achieve the same objective where a combination of the tokenization process, part-of-speech tagging and morphology analysis are all combined causing overlapping and ambiguity.

- Finally, the proposed scheme enables the introduction of different categories and types of tagsets and tag markers, whether they are related to basic syntactic and grammatical markers, functional markers, morphology related and semantic markers or any other type that might be needed for a specific objective. The expendability while maintaining clarity and simplicity is a powerful feature that maximizes the benefits of the proposed scheme. This can be observed in many samples in the previous table where explicit markers are used for different Arabic linguistic features e.g. active participle, passive participle, KANA and its sisters ... etc. Using such explicit markers can facilitate later efforts such as information extraction since these explicit markers can signal the existence of specific types of information.

\section{The Custom AnNotation ToOL}

To enable the proposed scheme, a Java based custom tool was prepared. We refer to this custom tool as the Bracket
Based Arabic Annotation (B2A2) tool as it employs brackets to establish morpho-syntactic compliant part-of-speech annotations for Arabic language.

Fig. 1 below presents a screenshot of the (B2A2) tool that demonstrates the tagging hierarchies (left) and the available tag markers (right). To commence with a new tagging process, a newline-terminated text file is uploaded into this tool where it will be initially bootstrap annotated using Stanford (POS) tagger. Later, the user uses the custom tool to review the initial annotations and modify/extend them accordingly. As demonstrated in the figure, the tool is delivered with an initial tagset where markers are classified into a number of categories e.g. base or lexical tags, functional tags, Arabic specific ... etc. These tags and tagsets can be easily modified and configured by the user who can introduce new tagsets or tag markers or modify the existing ones according to his needs. The modification for these markers can be introduced into the designated (tag_def) database table i.e. SQL Server database. The structure of the tag definition table is described in Table 3 next. The user can modify the markers themselves as well as their categorization. The custom tool dynamically incorporates any modifications on the markers or their categories during its initialization process. This dynamicity in marker definition as well as their utilization by the user allows users to use different formats for annotating the same word.

The variance in annotations is related to the defined tag markers, the required depth of coverage and richness of the annotation process as well as the user's linguistic proficiency.

Fig. 2 below demonstrates a screenshot of the (B2A2) tool, which clarifies how different annotations can be implemented for the same word according to the user's defined annotation guidelines.

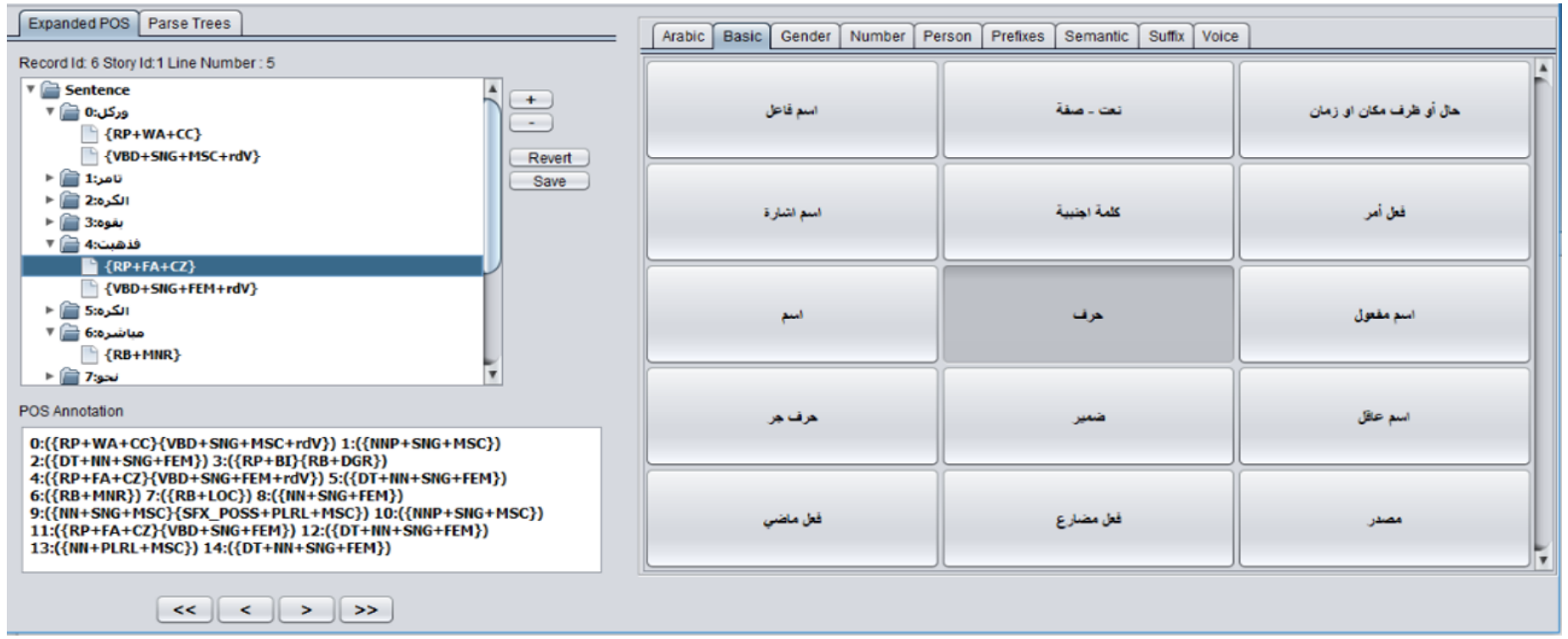

Fig. 1. The custom annotation tool. 

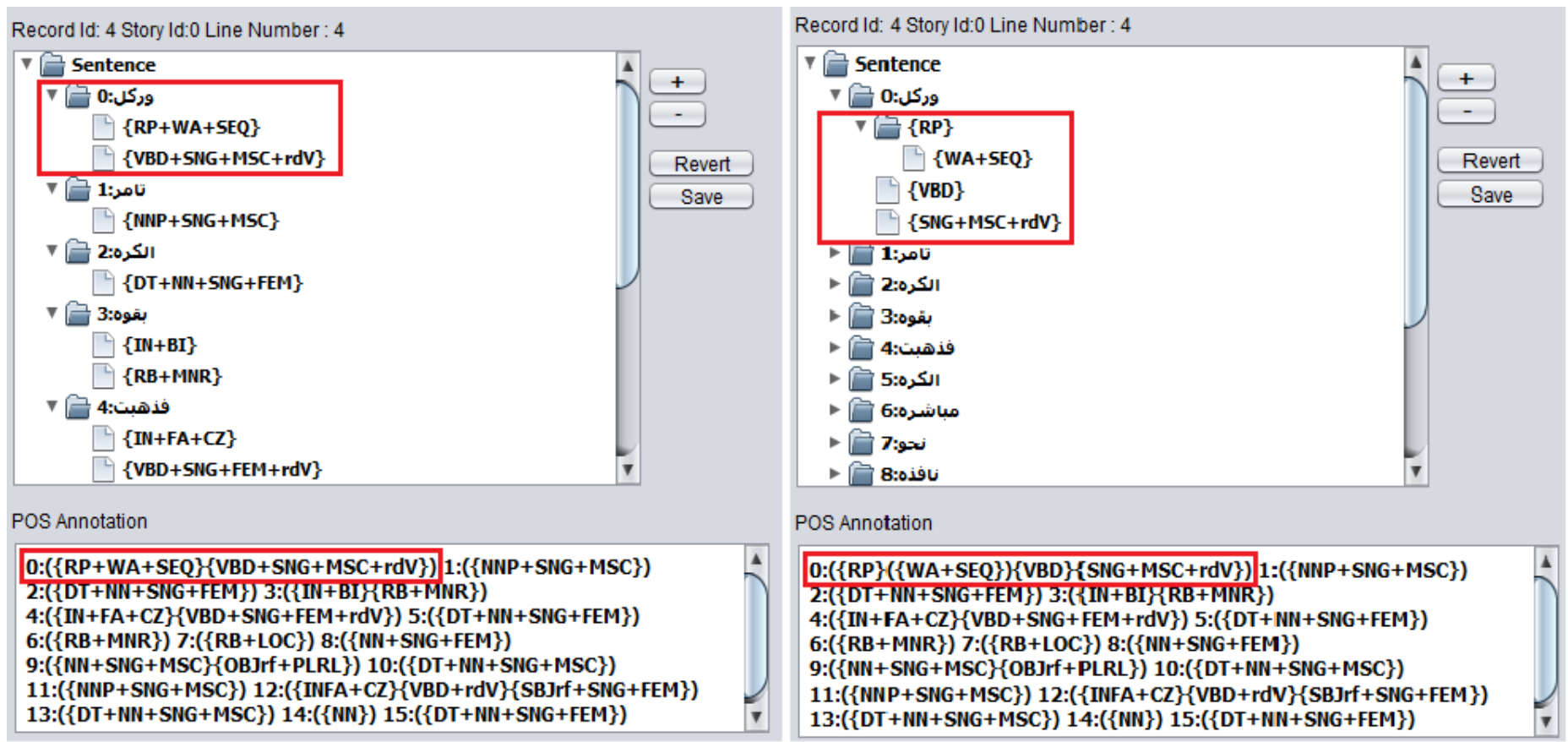

Fig. 2. Words and their constituents can be annotated different according to the user's definitions and requirements.

TABLE III. TAGS DEFINITION TABLE

\begin{tabular}{|l|l|l|}
\hline Column Id & Explanation & Example \\
\hline id & Unique identifier for the tag & \\
\hline tag_order & The order or the precedence of the tag within a composite annotation & 10 \\
\hline tag & The tag marker - acronym & RB \\
\hline short_name & The short name for the marker & Adverb \\
\hline english_description & English description for the marker & $\begin{array}{l}\text { An adverb is a word that changes or qualifies the meaning of a } \\
\text { verb. }\end{array}$ \\
\hline arabic_description & Arabic description for the marker & $\begin{array}{l}\text { The category where this marker belongs i.e. appears in the custom } \\
\text { tool }\end{array}$ \\
\hline tag_category & Lexical Markers \\
\hline
\end{tabular}

\section{ANNOTATING A SAMPLE NARRATIVE}

To assess the proposed scheme in action, we used the (B2A2) tool to annotate a sample narrative comprised of a few sentences. As discussed in the previous section, (B2A2) scheme provides different alternatives for annotating text in terms of the tag markers that can be used as well as their arrangement and grouping using brackets. In this respect, the following guidelines were defined and enforced during the annotation process:

- Verbs annotations were extended with number, gender and person markers.

- Verb prefixes were distinguished using custom particles tagging i.e. (واو WAW, فاء FA, سين SA...etc.).

- Nominals tagging was extended using number and gender markers.
- Noun and adjectives prefixes were distinguished using custom particles tagging i.e. (واو WAW, كاف KA, كاء BI ... etc.).

- A more precise tag set was used to annotate propositions i.e. (في GEE, من MIN, الى ELA ... etc.).

- Prefix particles, propositions and affixes where separated and grouped using dedicated brackets.

- Arabic (KANA, كان واخواتها, Was) was annotated using a custom tag (VBD+KANA) so that it can be better identified for future purposes.

- Occasionally during the annotation process, Arabic declension system was used in order to determine the correct grammatical analyses of some words and phrases so that ambiguous interpretations are resolved. 
TABLE IV. A SAMPLE Story ANNOtATEd USING THE Custom SChEME

\begin{tabular}{|c|c|}
\hline $\begin{array}{c}\text { Line } \\
\#\end{array}$ & Text and (POS) Annotation \\
\hline \multirow[b]{2}{*}{1} & |هدت:0 ليلى: 1 شقيقها:2 تامر:3 كره:4 جديده،:5 \\
\hline & $\begin{array}{l}0:(\{\mathrm{VBD}+\mathrm{SNG}+\mathrm{FEM}+\mathrm{rdV}\}) 1:(\{\mathrm{NNP}+\mathrm{SNG}+\mathrm{FEM}\}) \\
2:(\{\mathrm{NN}+\mathrm{SNG}+\mathrm{MSC}\}\{\mathrm{POSS}+\mathrm{SNG}+\mathrm{FEM}\}) \\
3:(\{\mathrm{NNP}+\mathrm{SNG}+\mathrm{MSC}\}) \\
3:(\{\mathrm{NN}+\mathrm{SNG}+\mathrm{FEM}\}) \\
5:(\{\mathrm{JJ}+\mathrm{SNG}+\mathrm{FEM}\})\end{array}$ \\
\hline \multirow[b]{2}{*}{2} & وكان:0 تامر:1 سعيدا:2 جدا:3 بها.:4 \\
\hline & $\begin{array}{l}0:(\{\mathrm{WA}+\mathrm{RP}+\mathrm{CC}\}\{\mathrm{KANA}+\mathrm{VBD}+\mathrm{SNG}+\mathrm{MSC}+\mathrm{rdV}\}) \\
1:(\{\mathrm{NNP}+\mathrm{SNG}+\mathrm{MSC}\}) \\
2:(\{\mathrm{JJ}+\mathrm{SNG}+\mathrm{MSC}\}) \\
3:(\{\mathrm{RB}+\mathrm{MNR}\}) 4:\left(\{\mathrm{IN}+\mathrm{BI}\}\left\{\mathrm{SFX} \_\mathrm{SUBJ}+\mathrm{SNG}+\mathrm{FEM}\right\}\right)\end{array}$ \\
\hline \multirow[b]{2}{*}{3} & ركض:0 تامر:1 نحو:2 الحديقه:3 ليلعب:4 بكرته:5 الجديده:6 \\
\hline & $\begin{array}{l}0:(\{\mathrm{VBD}+\mathrm{SNG}+\mathrm{MSC}+\mathrm{rdV}\}) 1:(\{\mathrm{NNP}+\mathrm{SNG}+\mathrm{MSC}\}) \\
2:(\{\mathrm{RB}+\mathrm{LOC}\}) \\
3:(\{\mathrm{DT}+\mathrm{NN}+\mathrm{SNG}+\mathrm{FEM}\}) \\
4:(\{\mathrm{IN}+\mathrm{LI}+\mathrm{CZ}\}\{\mathrm{VBP}+\mathrm{SNG}+\mathrm{MSC}+\mathrm{rdV}\}) \\
5:(\{\mathrm{IN}+\mathrm{BI}\}\{\mathrm{NN}+\mathrm{SNG}+\mathrm{FEM}\}\{\mathrm{POSS}+\mathrm{SNG}+\mathrm{MSC}\}) \\
6:(\{\mathrm{DT}+\mathrm{JJ}+\mathrm{SNG}+\mathrm{FEM}\})\end{array}$ \\
\hline \multirow[b]{2}{*}{4} & 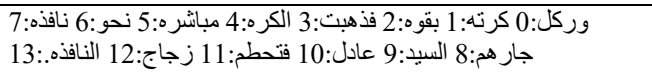 \\
\hline & 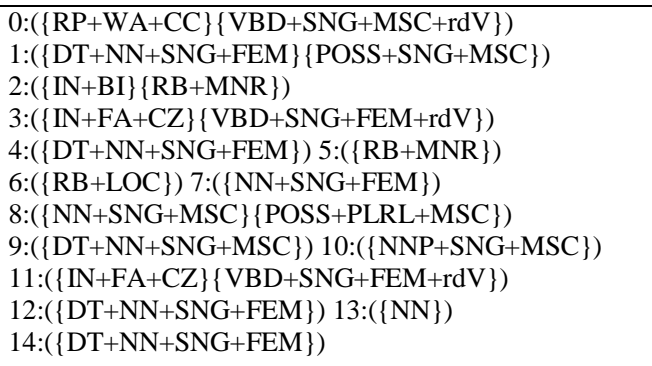 \\
\hline \multirow[b]{2}{*}{5} & راى:0 تامر:1 السيد:2 عادل:3 قادما:4 الى:5 منزله،:6 \\
\hline & $\begin{array}{l}0:(\{\mathrm{VBD}+\mathrm{SNG}+\mathrm{MSC}+\mathrm{rdV}\}) \\
1:(\{\mathrm{NNP}+\mathrm{SNG}+\mathrm{MSC}+\mathrm{rdV}\}) 2:(\{\mathrm{DT}+\mathrm{NN}+\mathrm{SNG}+\mathrm{MSC}\}) \\
3:(\{\mathrm{NNP}+\mathrm{SNG}+\mathrm{MSC}\}) 4:(\{\mathrm{AP}+\mathrm{SNG}+\mathrm{MSC}\}) \\
5:(\{\mathrm{IN}+\mathrm{ELA}\}) \\
6:(\{\mathrm{NN}+\mathrm{SNG}+\mathrm{MSC}\}\{\mathrm{POSS}+\mathrm{SNG}+\mathrm{MSC}\})\end{array}$ \\
\hline \multirow[b]{2}{*}{6} & فخاف:0 و اختبا:1 خلف:2 شجره:3 \\
\hline & $\begin{array}{l}0:(\{\mathrm{IN}+\mathrm{FA}+\mathrm{CZ}\}\{\mathrm{VBD}+\mathrm{SNG}+\mathrm{MSC}+\mathrm{rdV}\}) \\
1:(\{\mathrm{RP}+\mathrm{WA}+\mathrm{CC}\}\{\mathrm{VBD}+\mathrm{SNG}+\mathrm{MSC}+\mathrm{rdV}\}) \\
2:(\{\mathrm{RB}+\mathrm{LOC}\}) 3:(\{\mathrm{NN}+\mathrm{SNG}+\mathrm{FEM}\})\end{array}$ \\
\hline \multirow[b]{2}{*}{7} & راى:0 السيد:1 عادل:2 تامر:3 مختبئا:4 وابتسم:5 وقال:6 لا:7 تخغبيى:8 \\
\hline & $\begin{array}{l}0:(\{\mathrm{VBD}+\mathrm{SNG}+\mathrm{MSC}+\mathrm{rdV}\}) 1:(\{\mathrm{DT}+\mathrm{NN}+\mathrm{SNG}+\mathrm{MSC}\}) \\
2:(\{\mathrm{NNP}+\mathrm{SNG}+\mathrm{MSC}\}) 3:(\{\mathrm{NNP}+\mathrm{SNG}+\mathrm{MSC}\}) \\
4:(\{\mathrm{AP}+\mathrm{SNG}+\mathrm{MSC}\}) \\
5:(\{\mathrm{RP}+\mathrm{WA}+\mathrm{CC}\}\{\mathrm{VBD}+\mathrm{SNG}+\mathrm{MSC}+\mathrm{rdV}\}) \\
6:(\{\mathrm{RP}+\mathrm{WA}+\mathrm{CC}\}\{\mathrm{VBD}+\mathrm{SNG}+\mathrm{MSC}+\mathrm{rdV}\}) \\
7:(\{\mathrm{RP}+\mathrm{DMND}+\mathrm{NEG}\}) 8:(\{\mathrm{VBP}+\mathrm{SNG}+\mathrm{MSC}+\mathrm{ndV}\}) \\
9:(\{\mathrm{RP}+\mathrm{YAA}\}) \\
10:(\{\mathrm{JJ}+\mathrm{SNG}+\mathrm{MSC}\}\{\mathrm{POSS}+\mathrm{SNG}+\mathrm{MSC}\})\end{array}$ \\
\hline \multirow[b]{2}{*}{8} & اخبرني:0 الحقيق:11 و لا:2 تخف:3 \\
\hline & $\begin{array}{l}0:(\{\mathrm{VMP}+\mathrm{SNG}+\mathrm{MSC}\}\{\mathrm{PRN}+\mathrm{SNG}+\mathrm{MSC}\}) \\
1:(\{\mathrm{DT}+\mathrm{NN}+\mathrm{SNG}+\mathrm{FEM}\}) \\
2:(\{\mathrm{RP}+\mathrm{WA}+\mathrm{CC}\}\{\mathrm{RP}+\mathrm{DMND}+\mathrm{NEG}\}) \\
3:(\{\mathrm{VBP}+\mathrm{SNG}+\mathrm{MSC}+\mathrm{ndV}\})\end{array}$ \\
\hline \multirow[t]{2}{*}{9} & 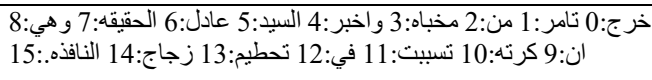 \\
\hline & $0:(\{\mathrm{VBD}+\mathrm{SNG}+\mathrm{MSC}+\mathrm{rdV}\}) 1:(\{\mathrm{NNP}+\mathrm{SNG}+\mathrm{MSC}\})$ \\
\hline
\end{tabular}

\begin{tabular}{|c|c|}
\hline & $\begin{array}{l}\text { 2:(\{IN+MEN\}) } \\
3:(\{\mathrm{NN}+\mathrm{SNG}+\mathrm{MSC}\}\{\mathrm{POSS}+\mathrm{SNG}+\mathrm{MSC}\}) \\
4:(\{\mathrm{RP}+\mathrm{WA}+\mathrm{SEQ}\}\{\mathrm{VBD}+\mathrm{SNG}+\mathrm{MSC}\}) \\
5:(\{\mathrm{DT}+\mathrm{NN}+\mathrm{SNG}+\mathrm{MSC}\}) 6:(\{\mathrm{NNP}+\mathrm{SNG}+\mathrm{MSC}\}) \\
\text { 7:(\{DT+NN+SNG+FEM }\}) \\
8:(\{\mathrm{RP}+\mathrm{WA}+\mathrm{CC}\}\{\mathrm{PRN}+\mathrm{SNG}+\mathrm{FEM}+\mathrm{rdV}\}) \\
\text { 9:(\{RP+ASRT}\}) \\
10:(\{\mathrm{NN}+\mathrm{SNG}+\mathrm{FEM}\}\{\mathrm{POSS}+\mathrm{SNG}+\mathrm{MSC}\}) \\
11:(\{\mathrm{VBD}+\mathrm{SNG}+\mathrm{FEM}+\mathrm{rdV}\}) 12:(\{\mathrm{NN}\}) \\
13:(\{\mathrm{DT}+\mathrm{NN}+\mathrm{SNG}+\mathrm{FEM}\})\end{array}$ \\
\hline & وتاسف:0 وو عده:1 الا:2 يكرر:3 هذا:4 الفعل:5 مره:6 اخرى.7 \\
\hline 10 & $\begin{array}{l}0:(\{\mathrm{RP}+\mathrm{WA}+\mathrm{CC}\}\{\mathrm{VBD}+\mathrm{SNG}+\mathrm{MSC}\}) \\
1:(\{\mathrm{NNP}+\mathrm{SNG}+\mathrm{MSC}\}) \\
2:(\{\mathrm{RP}+\mathrm{WA}+\mathrm{CC}\}\{\mathrm{VBD}+\mathrm{SNG}+\mathrm{MSC}+\mathrm{rdV}\}\{\mathrm{SFX} \mathrm{OBJ}+ \\
\text { SNG+MSC }\}) 3:(\{\mathrm{RP}+\mathrm{CNF}\}\{\mathrm{RP}+\mathrm{NEG}\}) \\
4:(\{\mathrm{VBP}+\mathrm{SNG}+\mathrm{MSC}+\mathrm{rdV}\}) 5:(\{\mathrm{RPRN}+\mathrm{SNG}+\mathrm{MSC}\}) \\
6:(\{\mathrm{NN}+\mathrm{SNG}+\mathrm{FEM}\}) 7:(\{\mathrm{NN}\})\end{array}$ \\
\hline & 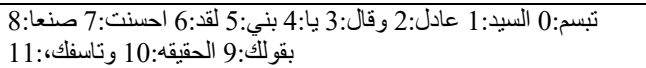 \\
\hline 11 & $\begin{array}{l}0:(\{\mathrm{VBP}+\mathrm{SNG}+\mathrm{MSC}+\mathrm{rdV}\}) 1:(\{\mathrm{DT}+\mathrm{NN}+\mathrm{SNG}+\mathrm{MSC}\}) \\
2:(\{\mathrm{NNP}+\mathrm{SNG}+\mathrm{MSC}\}) \\
3:(\{\mathrm{RP}+\mathrm{WA}+\mathrm{CC}\}\{\mathrm{VBD}+\mathrm{SNG}+\mathrm{MSC}+\mathrm{rdV}\}) \\
4:(\{\mathrm{RP}+\mathrm{YAA}\}) \\
5:(\{\mathrm{NN}+\mathrm{SNG}+\mathrm{MSC}\}\{\mathrm{POSS}+\mathrm{SNG}+\mathrm{MSC}\}) \\
6:(\{\mathrm{RP}+\mathrm{CNFRM}\}) 7:(\{\mathrm{VBD}+\mathrm{SNG}+\mathrm{MSC}+\mathrm{ndV}\}) \\
8:(\{\mathrm{VN}\}) 9:(\{\mathrm{IN}+\mathrm{BI}\}\{\mathrm{VBG}+\mathrm{SNG}+\mathrm{MSC}+\mathrm{ndV}\}) \\
10:(\{\mathrm{DT}+\mathrm{NN}+\mathrm{SNG}+\mathrm{FEM}\}) \\
11:(\{\mathrm{RP}+\mathrm{WA}+\mathrm{CC}\}\{\mathrm{VN}+\mathrm{SNG}+\mathrm{MSC}\}\{\mathrm{POSS}+\mathrm{SNG}+\mathrm{MS} \\
\mathrm{C}\})\end{array}$ \\
\hline & الان:0 خذ:1 الكره:2 وارجو:3 ان:4 لا:5 يتكرر:6 مثل:7 هذا:8 الفعل:9 \\
\hline 12 & $\begin{array}{l}0:(\{\mathrm{RP}+\mathrm{WA}+\mathrm{CC}\}\{\mathrm{RB}+\mathrm{TIM}\}) \\
1:(\{\mathrm{VMP}+\mathrm{SNG}+\mathrm{MSC}+\mathrm{ndV}\}) \\
2:(\{\mathrm{DT}+\mathrm{NN}+\mathrm{SNG}+\mathrm{FEM}\}) \\
3:(\{\mathrm{RP}+\mathrm{WA}+\mathrm{CC}\}\{\mathrm{VBP}+\mathrm{SNG}+\mathrm{stV}\}) 4:(\{\mathrm{IN}+\mathrm{CNFRM}\}) \\
5:(\{\mathrm{RP}+\mathrm{NEG}\}) 6:(\{\mathrm{VBP}+\mathrm{SNG}+\mathrm{MSC}\}) 7:(\{\mathrm{NN}\}) \\
8:(\{\mathrm{DT}+\mathrm{SNG}+\mathrm{MSC}+\mathrm{NR}\}) 9:(\{\mathrm{DT}+\mathrm{VN}+\mathrm{SNG}+\mathrm{MSC}\}) \\
10:(\{\mathrm{JJ}\})\end{array}$ \\
\hline
\end{tabular}

The result of annotation the sample narrative is presented in Table 4 above. For example, the noun (شققيها, shaqequha, her brother) was annotated using two segments, the first one belongs to the noun part along with its inflection, and the second is related to the attached pronoun suffix. The first part is annotated using $\{\mathrm{NN}+\mathrm{SNG}+\mathrm{MSC}\}$ tag group while the second part is annotated using the $\{\mathrm{POSS}+\mathrm{SNG}+\mathrm{FEM}\}$ tag group. As presented, each part is identified using a pair of curly brackets while the whole word (multi-token word) is grouped using a pair of parenthesis.

The annotation process demonstrated the efficiency of the proposed tagging scheme in representing the required syntactic and morphological information in simple yet rich manner. Further, the (B2A2) tool provided an enabling framework that accelerated the process of revising the automatically generated Part-of-Speech tagging and facilitated extending it using the proposed tagging scheme.

The proposed framework (the proposed Part-of-Speech tagging scheme and the B2A2 tool) can serve in numerous scenarios where the user is in a need to annotate a given corpus using a rich morpho-syntactic annotation while that labeled corpus can be used later for different Natural Language Processing (NLP) implementations e.g. Information Extraction from text. 


\section{CONCLUSION AND FUTURE WORK}

This paper presented a proposed scheme for Arabiccompliant part-of-speech tagging (POST).

Acknowledging the complexity and the richness of Arabic language, along with the shortages in the related standardizations, efforts and resources, the proposed (POST) scheme presented new perspectives that might assist in enhancing Arabic-based part-of-speech tagging process as well as opening doors for new perspectives and insights to regular such efforts.

The theme of the proposed model is relatively simple and straightforward yet powerful and capable in representing different types of information specific to Arabic language and its declension system. This scheme is based on: 1) using welldefined atomic part-of-speech markers; and 2) grouping these markers using two types of brackets, the curly brackets for sub-word level and the parenthesis for the word level of groupings.

A custom tool that is bootstrapped using Stanford (POS) tagger enabled the initial version of the proposed (POST) scheme. This tool is freely available online and it can assist users to commence with a rich Part-of-Speech tagging process in a controllable and seamless manner.

The next work we intend to implement is to examine the benefits that can be achieved by using the proposed scheme in information extraction implementations. In addition, we intend to investigate the bootstrapping of the enabling tool using a morphology aware part-of-speech tagging library, e.g., MADAMIRA.

\section{REFERENCES}

[1] S. Alqrainy, "A Morphological - Syntactical Analysis," 2008.

[2] R. A. Abumalloh, H. M. Al-Sarhan, O. Bin Ibrahim, and W. Abu-Ulbeh, “Arabic Part-of-Speech Tagging," J. Soft Comput. Decis. Support Syst., vol. 3, no. 2, pp. 45-52, 2016.

[3] A. Boudlal, A. Lakhouaja, A. Mazroui, A. Meziane, M. Ould Abdallahi Ould Bebah, and M. Shoul, "Alkhalil Morpho SYS1: A Morphosyntactic Analysis System for Arabic Texts," Int. Arab Conf. Inf. Technol., pp. 1-6, 2010.

[4] S. Alqrainy, A. Ayesh, and H. Almuaidi, "Automated Tagging System And Tagset Design For Arabic Text," vol. 1, no. 2, pp. 55-62, 2010.

[5] A. M. S. Alosaimy and E. S. Atwell, "A review of morphosyntactic analysers and tag-sets for Arabic corpus linguistics," Corpus Linguist. 2015, pp. 16-19, 2015.

[6] N. Habash, R. Faraj, and R. Roth, "Syntactic Annotation in the Columbia Arabic Treebank," Proc. MEDAR Int. Conf. Arab. Lang. Resour. Tools, Cairo, Egypt, pp. 125-132, 2009.

[7] F. Al-shargi and O. Rambow, "DIWAN : A Dialectal Word Annotation Tool for Arabic," pp. 49-58, 2015.

[8] M. Attia, "An Ambiguity-Controlled Morphological Analyzer for Modern Standard Arabic Modelling Finite State Networks," Challenges Arab. NLP/MT Conf. ..., pp. 48-67, 2006.
[9] M. Sawalha, E. Atwell, and M. a. M. Abushariah, "SALMA Standard Arabic Language Morphological Analysis," Proceedings ICCSPA International Conference on Communications, Signal Processing, and their Applications. Sharjah, UAE, 2013. [Online]. Available: http://www.comp.leeds.ac.uk/eric/sawalha13iccspa.pdf. [Accessed: 23Dec-2015]

[10] N. Y. Habash, "Introduction to Arabic Natural Language Processing," Synth. Lect. Hum. Lang. Technol., vol. 3, no. 1, pp. 1-187, 2010.

[11] Y. O. M. Elhadj, A. Abdelali, R. Bouziane, and A. H. Ammar, "Revisiting Arabic Part of Speech Tagsets," Proc. IEEE/ACS Int. Conf. Comput. Syst. Appl. AICCSA, vol. 2014, pp. 793-802, 2014.

[12] S. Khoja, "APT : Arabic Part-Of-speech Tagger," Proc. Student Work. NAACL, pp. 20--25, 2001.

[13] M. Maamouri and A. Bies, "Developing an Arabic treebank: methods, guidelines, procedures, and tools," Proc. Work. Comput. Approaches to Arab. Script-based Lang., pp. 2-9, 2004.

[14] T. Buckwalter, "Arabic Morphological Analyser Version 1.0," Linguist. Data Consort. numéro LDC2002L49, 2002.

[15] J. Hajič, O. Smrž, P. Zemánek, J. Šnaidauf, and E. Beška, "Prague Arabic Dependency Treebank Development in Data and Tools," Proc. $\{\{\}$ NEMLAR \{\}$\}$ Int. Conf. $\{\{\} A\{\}\}$ rabic Lang. Resour. Tools, pp. 110-117, 2004.

[16] O. Smrž, J. Šnaidauf, and P. Zemánek, "Prague Dependency Treebank for Arabic: Multi-Level Annotation for Arabic Corpus," Adv. Math. (N. Y)., vol. 217, no. 6, pp. 2401-2442, 2008.

[17] N. Habash and R. M. Roth, "CATiB: the Columbia Arabic Treebank," '09 Proc. ACL-IJCNLP 2009 Conf., no. August, pp. 221-224, 2009.

[18] R. Al-sabbagh and R. Girju, "Supervised POS Tagger for Written Arabic Social Networking Corpora," Proc. KONVENS 2012 (Main track oral Present. Vienna, Sept. 19, vol. 2012, pp. 39-52, 2012.

[19] C. D. Manning, J. Bauer, J. Finkel, S. J. Bethard, M. Surdeanu, and D. McClosky, "The Stanford CoreNLP Natural Language Processing Toolkit," Proc. 52nd Annu. Meet. Assoc. Comput. Linguist. Syst. Demonstr., pp. 55-60, 2014.

[20] S. Bird, S. Bird, and E. Loper, "NLTK: The natural language toolkit NLTK: The Natural Language Toolkit," Proc. ACL-02 Work. Eff. tools Methodol. Teach. Nat. Lang. Process. Comput. Linguist. 1, no. March, pp. 63-70, 2016.

[21] A. Pasha, M. Al-badrashiny, M. Diab, A. El Kholy, R. Eskander, N. Habash, M. Pooleery, O. Rambow, and R. M. Roth, "MADAMIRA : A Fast , Comprehensive Tool for Morphological Analysis and Disambiguation of Arabic," Proc. 9th Lang. Resour. Eval. Conf., pp. 1094-1101, 2014.

[22] Y. Souteh and K. Bouzoubaa, "SAFAR platform and its morphological layer SAFAR platform and its morphological layer," no. December 2011, 2015.

[23] A. Bies and M. Maamouri, "Penn Arabic Treebank Guidelines," Draft January, vol. 28, no. December, p. 2003, 2003.

[24] N. Habash, O. Rambow, and R. Roth, "MADA+TOKAN: A Toolkit for Arabic Tokenization, Diacritization, Morphological Disambiguation, POS Tagging, Stemming and Lemmatization," Proc. Second Int. Conf. Arab. Lang. Resour. Tools, no. November 2015, pp. 102-109, 2009.

[25] G. Leech and A. Wilson, "EAGLES recommendations for the morphosyntactic annotation of corpora," Version of March, 1996.

[26] N. Habash, O. Rambow, and R. Roth, "MADA+TOKAN Manual," 2010.

Appendix A. Initial Part-of-Speech Tagset

\begin{tabular}{|c|c|c|c|c|c|}
\hline \multicolumn{3}{|c|}{ Lexical Markers } & \multicolumn{3}{|c|}{ Functional Markers - Semantic Driven } \\
\hline $\mathrm{NN}$ & Noun & اسم & LOC & Location & دلالة مكانية \\
\hline $\mathrm{JJ}$ & Adjective & نعت - صفة & TIM & Time & دلالة زمانية \\
\hline $\mathrm{RB}$ & Adverb & حال أو ظرف مكان او & $\mathrm{CZ}$ & Cause & دلالة سبب \\
\hline
\end{tabular}




\begin{tabular}{|c|c|c|c|c|c|}
\hline $\mathrm{RP}$ & Particle & حرف & EFCT & Effect & دلالة النتيجة \\
\hline IN & Preposition & حرف جر & SEQ & Sequence & دلالة تتابع \\
\hline$\overline{P R N}$ & Pronoun & ضمير & BGN & Begin of & دلالة بداية وقت \\
\hline DT & Determiner & اسم اشـارة & END & End of & دلالة نهاية وقت \\
\hline VBP & Verb Present & فعل مضارع & CND & Condition & دلالة شرط \\
\hline VBD & Verb Past & فعل ماضي & $\mathrm{CNF}$ & Confirmation & دلالة توكيد \\
\hline NNP & Proper Name & اسم عاقل & ASRT & Assertion & دلالة اخبار \\
\hline FW & Foreign Word & كلمة اجنبية & $\mathrm{CC}$ & Conjunction & دلالة عطف \\
\hline VN & Verbal Noun & مصدر & INTR & Interrogative & دلالة استفهام \\
\hline $\mathrm{PP}$ & Passive Participle & اسم مفعول & QTY & Quantity & دلالة كميات \\
\hline$\overline{\mathrm{AP}}$ & Active Participle & اسم فاعل & NEG & Negation & دلالة نفي \\
\hline VMP & Imperative & فعل أمر & EXP & Explanation & دلالة تفسير \\
\hline RPRN & Relative Pronoun & اسم موصول & DMN & Demand & دلالة طلب \\
\hline WP & Wh-pronoun & اسم استفهام & PRD & Predicate & خبر \\
\hline \multicolumn{3}{|c|}{ Number Markers } & PRD & Predicate & WHY \\
\hline SNG & Single & مفرد & WHN & When & استفسار متى \\
\hline DUAL & Dual & مثنى & HOW & How & استفسار كيف \\
\hline \multirow[t]{2}{*}{$\overline{\text { PLRL }}$} & Plural & جمع & WHO & Who & استفسار من \\
\hline & & & SWR & Swearing & دلالة قسم \\
\hline \multicolumn{3}{|c|}{ Gender Markers } & SWR & Swearing & MNR \\
\hline MSC & Masculine & مذكر & DGR & Degree & درجة الفعل \\
\hline \multirow[t]{2}{*}{ FEM } & Feminine & مؤنث & NR & Near & د الالة القرب \\
\hline & & & FR & Far & دلالة البعد \\
\hline \multicolumn{3}{|c|}{ Voice Markers } & \multicolumn{3}{|c|}{ Arabic Declension System Specifics } \\
\hline stV & First Voice & First Voice Verb & YAA & YAA & يا النداء \\
\hline $\mathrm{ndV}$ & Second Voice & $\begin{array}{l}\text { Second Voice } \\
\text { Indicator }\end{array}$ & KANA & KANA & كان و اخو اتها \\
\hline $\mathrm{rdV}$ & Third Voice & $\begin{array}{l}\text { Third Voice } \\
\text { Indicator }\end{array}$ & INNA & INNA & ان اخو اتها \\
\hline \multicolumn{3}{|c|}{ Active-Passive Markers } & ZRFL & Locative Adverb & ظرف مكان \\
\hline PSV & Absent Person & صيغة الغائب & ZRFZ & Temporal Adverb & ظرف زمان \\
\hline ATV & Present Person & صيغة الحاضر & CSA & $\begin{array}{l}\text { Accusative Case } \\
\text { Ending }\end{array}$ & علامة النصب \\
\hline \multicolumn{3}{|c|}{ Suffix Markers } & $\mathrm{CSN}$ & $\begin{array}{l}\text { Nominative Case } \\
\text { Ending }\end{array}$ & علامة الرفع \\
\hline SFX & Attached Pronoun & ضمير منصل & CSG & $\begin{array}{l}\text { Genitive Case } \\
\text { Ending }\end{array}$ & علامة الكسر \\
\hline POSS & Possession & مؤشر على الملكية & CSNU & Nunation Case & علامة التنوين \\
\hline$\overline{\text { OBJ }}$ & Object Reference & مؤشر على المفعول به & AAN & AAN & عن \\
\hline \multicolumn{3}{|c|}{ Prefix Markers - Functional Particles } & ALA & ALA & على \\
\hline $\mathrm{BI}$ & $\mathrm{BI}$ & باء & FEE & FEE & في \\
\hline LI & LI & لام & MEN & MEN & من \\
\hline FA & FA & فاء & HATTA & HATTA & حتى \\
\hline SA & SA & سين & ELA & ELA & 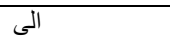 \\
\hline WA & Waw & واو & SBJ & Subject Reference & مؤشر على الفاعل \\
\hline
\end{tabular}

